\title{
Pengembangan Buku Ajar Digital Parenting: Strategi Perlindungan Anak Usia Dini
}

\author{
Maulidya Ulfah ${ }^{1 凶}$ Maemonah $^{2}$, Sigit Purnama ${ }^{3}$, Nur Hamzah ${ }^{4}$, Elfan Fanhas Fatwa ${ }^{5}$ \\ Pendidikan Islam Anak Usia Dini, Institut Agama Islam Negeri Syekh Nurjati Cirebon, \\ Indonesia(1), Pendidikan Guru Madrasah Ibtidaiyah, UIN Sunan Kalijaga Yogyakarta, \\ Indonesia(2), Pendidikan Islam Anak Usia Dini, UIN Sunan Kalijaga Yogyakarta, Indonesia(3), \\ Pendidikan Islam Anak Usia Dini, Institut Agama Islam Negeri Pontianak, Indonesia(4), \\ Pendidikan Guru Pendidikan Anak Usia Dini, Universitas Muhammadiyah Tasikmalaya, \\ Indonesia( ${ }^{(5)}$
}

DOI: $\underline{10.31004 / \text { obsesi.v6i3.1773 }}$

\begin{abstract}
Abstrak
Penggunaan teknologi yang tidak semestinya mengakibatkan adanya digital kidnapping, cyberbullying, child grooming, kecanduan gawai, pornografi, bahaya kesehatan dan radiasi. Penelitian ini bertujuan untuk menghasilkan produk berupa buku ajar digital parenting sebagai strategi perlindungan anak. Metode yang dipakai adalah penelitian dan pengembangan (RND) mengacu pada model pengembangan 4-D (define, design, develop dan desseminate). Produk divalidasi pakar media dan pakar ahli materi serta diuji cobakan kepada 15 orang tua anak selama 1 bulan. Teknik Pengumpulan data dengan menggunakan teknik observasi, angket, wawancara dan dokumentasi. Analisis tahap pertama dengan analisis deskriptif dan teknik analisis kualitas produk adalah analisis data deskriptif kuantitatif. Pengembangan isi buku yaitu bahaya dunia online, konsep digital parenting, pengasuhan anak, bersahabat dengan media digital dan sinergi peran dari orang tua dan sekolah dalam melindungi anak. Penelitian ini menunjukkan hasil bahwa buku yang dinyatakan layak digunakan dengan hasil dari ahli media $85 \%$, ahli materi $82 \%$, pengguna $88,3 \%$ dan nilai rata-rata $85,1 \%$.
\end{abstract}

Kata Kunci: digital parenting; perlindungan anak; bahaya dunia online

\begin{abstract}
Improper use of technology results in digital kidnapping, cyberbullying, child grooming, gadget addiction, pornography, health hazards and radiation. This study aims to produce a product in the form of a digital parenting textbook as a child protection strategy. The method used is research and development (RND) refers to the 4-D development model (define, design, develop and desseminate). The product was validated by media experts and material experts and tested on 15 children's parents for 1 month. Data collection techniques using observation, questionnaires, interviews and documentation. The first stage of analysis with descriptive analysis and product quality analysis techniques is quantitative descriptive data analysis. The development of the contents of the book, namely the dangers of the online world, the concept of digital parenting, child care, friendship with digital media and the synergy of the roles of parents and schools in protecting children. This study shows the results that the book is declared suitable for use with results from media experts $85 \%$, material experts $82 \%$, users $88.3 \%$ and an average value of $85.1 \%$.

Keywords: digital parenting; child protection; the dangers of the online world
\end{abstract}

Copyright (c) 2021 Maulidya Ulfah, et al.

$\triangle$ Corresponding author:

Email Address : ulfah@syekhnurjati.ac.id (Cirebon_Jawa Barat)

Received 30 May 2021, Accepted 19 September 2021, Published 22 September 2021 


\section{PENDAHULUAN}

Penelitian ini mengkaji secara komprehensif digital parenting dan perlindungan anak usia dini secara kolaboratif dan integratif. Namun realitanya kajian kedua hal tersebut masih dikotomis, berdiri sendiri-sendiri (independensi). Secara yuridis hak anak adalah mendapatkan perlindungan telah tertuang dalam UU RI No. 35 tahun 2014 (Undang-Undang RI No. 35 Tahun 2014 , n.d.) yaitu dijamin, dilindungi orang tua, keluarga, masyarakat, Negara dan Pemerintah. Dalam Permen PPPA RI No. 2 dan 6 tahun 2011 menjelaskan bahwa hak anak termasuk dalam perlindungan penggunaan teknologi yang bebas dari konten kekerasan dan pornografi sehingga mengakibatkan tumbuh kembang dapat terganggu (Peraturan Menteri Negara Pemberdayaan Perempuan Dan Perlindungan Anak Nomor 2 Tahun 2011 Tentang Pedoman Penanganan Anak Korban Kekerasan, n.d.). Namun hasil temuan yang terekam oleh Komisi Perlindungan Anak Indonesia (KPAI) dalam kasus kekerasan pada anak, jumlahnya semakin banyak yakni tahun 2019 saja itu jumlah kasus 6225.

Pada tahun 2018 data dari 4.885, pencapaian pertama adalah 1.434 kasus anak berhadapan dengan hukum (kekerasan seksual), rangking kedua 857 kasus terkait keluarga dan pengasuhan alternatif dan rangking ketiga yaitu 679 kasus pornografi dan siber yang didominasi oleh 134 kasus, sedangkan bullying mencapai 112 kasus. (Setyawan, 2019). Hasil riset terkait kekerasan pada anak diantaranya adalah kasus bullying yang ditemukan di Taman Kanak-kanak Padang diklasifikasikan menjadi tiga, yaitu: fisik (memukul, menendang, mencubit, merusak mainan teman, mendorong), bullying verbal (mengolok, memarahi, mengancam, mengejek) dan bullying psikologis (mengucilkan, menyendiri, murung, menangis karena ditertawakan (Wahyuni \& Pransiska, 2019) Selain itu, kidnapping yang merupakan kejahatan dengan menculik seseorang dengan tujuan pemerasan (Basiang, 2016) diadopsi secara illegal dan karena dendam (Agung et al., 2020) Berdasarkan riset diantaranya ditemukan di Bali pada anak perempuan umur 6 tahun (Manik \& Widhiyaastuti, 2019) di wilayah Lampung Selatan seorang guru olah raga sekolah menculik 4 siswa (Fatonah et al., 2019).

Secara akademis, teknologi seperti sebilah pisau, netral yang memiliki dampak positif dan negatif. Menurut Badan Litbang SDM Kementerian Kominfo menyatakan sekitar tiga puluh juta anak-anak di Indonesia menggunakan internet dengan media digital. ("Riset Kominfo Dan UNICEF Mengenai Perilaku Anak Dan Remaja Dalam Menggunakan Internet," 2014) Gawai (gadget) telah mengubah pola pengasuhan anak karena segala aktivitas berhubungan dengan hal tersebut. (Purnama, Ulfah, et al., 2021) (Adelman \& Adelman, 2018). Hasil penelitian The Asian Parent Insights menunjukkan persentase sebesar 98\% dari sejumlah 2.714 orang tua di Asia Tenggara menyatakan telah mengijinkan anak-anak 3-8 tahun untuk memanfaatkan media digital seperti komputer, gawai (gadget). Berdasarkan hasil riset, orang tua mengijinkan anaknya bermain gawai (gadget) dengan tujuan mengedukasi (N. H. Hamzah et al., 2021). Namun realitanya, pemberian tersebut justru hanya untuk hiburan seperti bermain game (Alia \& Irwansyah, 2018) melihat video, berinteraksi dengan teman dan pemanfaatan media sosial. Dampak negatif yang banyak terjadi akibat dari hal tersebut berdsarkan survey di Jawabarat antara lain digital kidnapping, cyberbulllying, child grooming, kecanduan gawai, pornografi, kesehatan dan radiasi. (Ulfah, 2020). Kecanduan gawai (gadget) dapat mengakibatkan anak jarang beraktivitas melatih kemampuan motorik kasarnya, dapat menyebabkan obesitas, perkembangan sosial emosional anak kurang berkembang dan anak dapat mengalami keterlambatan kemampuan berbicara (Donnyanggoro et al., 2018).

Orang tua perlu menyusun strategi untuk melindungi hak anak dalam menggunakan media digital yaitu dengan menerapkan konsep digital parenting dengan menambah pengetahuan tentang pengasuhan anak di era digital dan bahaya media tersebut karena orang tua memiliki andil yang besar dalam menghasilkan generasi penerus yang berkarakter dan tangguh (Mansur, 2009). Digital parenting merupakan bagian dari parenting. Martin Davies, seorang profesor di Universitas East Anglia Inggris, menjelaskan bahwa parenting merupakan pendidikan sejak lahir pada anak sampai anak dewasa dengan kriteria yang ditentukan tidak 
sekedar pertumbuhan fisik namun dewasa baik mental maupun psikologis (Ratulia, 2015). Parenting merupakan komunikasi dan interaksi antara orang tua dengan anak-anak yang mencakup kegiatan memberikan perlindungan (protecting), memberikan petunjuk (guiding), memberikan nutrisi makanan (nourishing), saat tumbuh kembang anak-anak (Yani et al., 2017). Namun sampai saat ini belum ada sekolah untuk orang tua sehingga masih banyak ditemukan pola asuh warisan yang menyimpang karena merka tidak memahami ilmu parenting sementara kejahatan online semakin mengancam. Oleh karena itu "menghubungkan" (Barbour, 2002) parenting dengan perlindungan anak menjadi penting dan mendesak untuk dilakukan.

Peran orang tua saat mendidik anak dalam keluarga sangatlah sentral karena menjadi bagian dari tri pusat pendidikan anak-anak yang berpengaruh terhadap anak (Ulfa Maulidya, 2017; Risma et al., 2019). Pola asuh orang tua dalam pendidikan keluarga sebagai dasar dalam pembentukan karakter anak (Maulidya Ulfah, Ery Khaeriyah, 2018; Nurwita, 2019). Kemajuan teknologi menjadikan pengasuhan orang tua semakin mendesak agar anak tidak menjadi korban negative cyber (Rahmat, 2018). Semakin banyak keterlibatan orang tua dalam pengasuhan maka akan semakin berdampak positif terhadap perkembangan sosial emosi anak (Hayati \& Mamat, 2014).

Secara aktual, berdasarkan wawancara dengan 5 guru Satuan PAUD di Kota Cirebon, dapat dijelaskan bahwa dampak gawai (gadget) pada anak dapat dirasakan dengan menurunnya tingkat bersosialisasi anak. Selain itu, beberapa anak yang suka bermain gawai (gadget) mengalami delay speech atau keterlambatan dalam berbicara. Pengaruh media digital ini banyak dialami oleh anak laki-laki yang cenderung lebih agresif sehingga sering terjadi pertengkaran. Sementara orang tua tidak mampu mendidik di era digital menjadi salah satu munculnya peningkatan tindak kekerasan terhadap sesama anak usia dini. Berdasarkan pengamatan peneliti tersebut maka perlu adanya panduan secara kompehensif tentang digital parenting sebagai strategi perlindungan anak.

Konsep teori Baumrind menjelaskan pola asuh orang tua harus memenuhi kebutuhan anak, memberi perlindungan dan mempengaruhi perilaku anak. Model tipologi tripartite membagi pengasuhan menjadi authoritarian, autoritatif dan permisif (Baumrind, 1966) yang kemudian menjadi empat oleh Maccoby dan Martin yaitu pola asuh permisif, autoritatif, authoritarian dan uninvolved. Selain itu pengasuhan dalam kehidupan anak sebagai strategi perlindungan anak juga memperhatikan teorinya Urie Bronfenbrenner dalam pandangan ekologi bahwa pengasuhan anak dari lingkungan terdekat dari orang tua (mikrosistem) yang dipengaruhi oleh nilai budaya setempat (makrosistem) dan keseluruhan system yang melingkupi kehidupan anak seiring perkembangan zaman dikenal dengan chronosystem (Bronfenbrenner, 1994).

Hasil penelitian Sri Maisari dan Sigit Purnama menjelaskan bahwa digital parenting memiliki makna cara mengasuh anak dalam mengatur kebiasaan anak dalam menggunakan gawai (gadget). Maisari \& Purnama (2019) Lebih lanjut, kajian pustaka yang dilakukan oleh Purnama (2018) menjelaskan bahwa orang tua milenial perlu mengenali karakteristik generasi alpha agar dapat membimbing anak-anak berinteraksi secara cerdas dengan internet. Penelitian lain dilakukan oleh Maya Syulfharita P. dkk. kebiasaan memakai gawai (gadget) dalam waktu 2 sampai 3 jam tiap hari dengan persentase 66,2\% dan memiliki pengaruh terhadap kesehatan anak pengaruhnya dengan kesehatan mata pada usia 10-12 tahun masih dalam kondisi normal sebanyak 54 orang (79,4\%) (Pertiwi et al., 2018). Sementara penelitian Riris Eka Setiani (Setiani, 2016) menawarkan pendidikan anti kekerasan yang sistem dan prosesnya aman, nyaman dan menyenangkan sehingga tidak mengganggu proses tumbuh kembang anak. Penelitian Nur Intan Rochmawati dan Adhi Budi Susilo (Rochmawati \& Susilo, 2019) mengungkap upaya TK IT Bintang kecil dalam bentuk mengenalkan dan mencegah kekerasan pada anak dan sebagai upaya pengetahuan tentang perlindungan anak serta preventif agar kekerasan tidak semakin bertambah. 
Hampir semua penelitian di atas berbasis kualitatif deskriptif, studi kasus, kajian pustaka. Dalam penelitian ini difokuskan bagaimana mengembangkan buku panduan untuk dapat digunakan orang tua maupun guru yang disusun secara hierarki mengikuti perkembangan jaman sekarang yaitu era digital. Penelitian yang dilaksanakan peneliti menjadi sangat penting dalam pengembangan yang menghasilkan buku ajar digital parenting sebagai panduan untuk memberikan gambaran secara komprehensif tentang langkah-langkah dalam digital parenting sebagai strategi perlindungan anak dari bahaya media digital. Penelitian ini menjadi penelitian lanjutan dari penelitian tentang parenting sebelumnya (di atas) dan dapat memberikan sumbangsih kepada satuan PAUD dalam kegiatan parenting penting mengangkat tema digital parenting secara komprehensif sebagai upaya mewujudkan PAUD Holistik Integratif (Peraturan Presiden Nomor 60 Tahun 2013 Tentang Pengembangan Anak Usia Dini Yang Holistik Integratif, n.d.) (Ulfah, 2019) yakni diharapkan satuan PAUD menggiatkan kegiatan parenting sehingga ada keselarasan antara pendidikan sekolah dengan pendidikan di rumah.

\section{METODOLOGI}

Penelitian ini menggunakan R and D (Research and Development) (Sugiyono, 2012) untuk menghasilkan sebuah buku ajar digital parenting yang dapat dimanfaatkan oleh orang tua di rumah maupun guru di sekolah sesuai dengan kebutuhan. Model yang digunakan adalah model 4D (Four D) yang dikembangkan oleh Thiagarajan, memiliki 4 tahapan yang dilakukan, yaitu dapat tergambar dalam gambar 1. (Others et al., 1974).

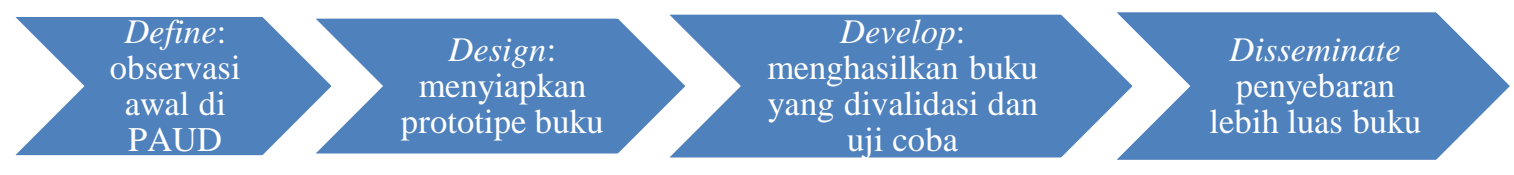

\section{Gambar 1. Langkah-langkah Penelitian}

Subjek dari penelitian adalah lima belas (15) orang tua di Jawa barat yang memiliki anak usia dini dari latarbelakang pendidikan maupun ekonomi yang berbeda dan dilaksanakan pada bulan Agustus sampai Desember 2020, semester gasal di tahun pelajaran 2020/2021.

Data dikumpulkan dengan berbagai teknik yakni menggunakan 4 metode: wawancara orang tua dan guru, observasi kegiatan parenting dan pengasuhan orang tua, angket untuk orang tua dan dokumentasi kegiatan pengasuhan oleh orang tua. Analisis data dalam penelitian ini menggunakan teknik analisis deskriptif dalam menganalisis saat observasi awal di Satuan PAUD Kota Cirebon kemudian hasil nilai validasi pakar dihitung menggunakan persentase yaitu kelayakan dari buku digital parenting. Nilai yang diperoleh dari presentase penilaian para pakar diantaranya adalah ahli materi, ahli media dan pengguna, maka selanjutnya data diubah ke dalam tabel untuk mempermudah membaca hasil penelitian. Data tersebut kemudian dideskripsikan dan diambil simpulan dengan menggunakan presentase kelayakan buku pada tabel dan adapun rumusnya sebagai berikut (Sugiyono, 2011).

Persentase kelayakan $(\%)=$ Skor yang di peroleh $\times 100 \%$

Skor maksimum

Berdasarkan rumus perhitungan tersebut, maka analisis validitas angket menggunakan skala likert dengan kriteria positif. Interval Skor Validasi Pakar Ahli Media dan Ahli Materi: 81,25\% - 100 \% (sangat baik), 62,50\% - 81,25 \% (baik), 43,27\% - 62, 50 \% (cukup). Uji keabsahan data dalam penelitian R\&D dilakukan dengan trianggulasi, yaitu sumber, metode dan waktu sehingga data yang dihasilkan akan semakin valid (Sugiyono, 2012). 
Buku ajar digital parenting dinyatakan dapat diterapkan oleh orang tua untuk mengasuh anak usia dini di era digital sebagai strategi perlindungan untuk anak usia dini sesudah divalidasi oleh pakar, mendapat tanggapan pihak sekolah dan orang tua dengan pengembangan termasuk kategori "baik". Buku ajar digital parenting akan efektif apabila skor orang tua dalam penggunaan mencapai minimal $75 \%$ atau masuk ke dalam klasifikasi baik maupun sangat baik, aktif maupun sangat aktif.

\section{HASIL DAN PEMBAHASAN}

Penelitian berbasis riset dan pengembangan yang mengacu model dari Thiagarajan dilaksanakan dengan menerapkan 4 langkah yang ditempuh yaitu pendefinisian, perancangan, pengembangan dan penyebaran. Pertama, tahap pendefenisian (Define) buku ajar digital parenting. Tahapan ini merupakan tahap sebelum merancang media berupa buku ajar digital parenting, yang terdiri dari 5 kegiatan menurut Thiagrajan (Others et al., 1974), yaitu: (a) Front and end analysis, yakni analisis awal dan akhir dari hasil observasi awal di sepuluh Satuan PAUD Jawa barat yang dipilih secara acak diantaranya PAUD Aisyiyah, RA Baiturrahman Kota Cirebon, TK Khalifah Kota Cirebon, PAUD Lebah Kecil Kota Cirebon, RA Ya Ibna Cimahi, RA Ulul Albab Cimahi, KB An Nahl Sukabumi, TK Kemala Bhayangkari, RA At Taqwa Cimahi dan TK Melati Indramayu. Tujuan tahap ini adalah untuk menemukan masalah yang dirasakan orang tua saat mengasuh anaknya dalam menggunakan gawai (gadget). Pada tahap ini, ditemukan hampir semua orang tua meminjamkan anaknya gawai (gadget), bahkan ada yang sampai kecanduan gawai. Sementara banyak orang tua yang belum memahami tentang kejahatan di dunia online seperti digital kidnapping, child grooming, pornografi, dampak negatif untuk kesehatan dan radiasi. Beberapa orang tua memahami tentang cyberbulllying dan kecanduan gawai sebagai dampak negatif karena ditemukan anakanak yang demikian. Selain itu, pengetahuan orang tua untuk melindungi anak dari bahaya tersebut masih belum optimal seperti tips berinternet yang aman, sehat dan menyenangkan.

Tahapan selanjutnya dari 5 kegiatan merancang media adalah (b) Learner analysis, yaitu karakteristik orang tua dan anak baik kemampuan, motivasi dan pengalaman dalam penggunaan gawai (gadget). Analisis ini menjadi bagian dari hasil observasi tahap 1 dan menjadi bagian dari tema/ outline buku ajar yakni bahwa anak usia dini termasuk dalam anak digital native, mereka adalah anak generasi alpha (Purnama, 2018) yang sejak dilahirkan sudah tidak asing dengan media digital. Berdasarkan hasil observasi anak-anak memiliki usia 4-6 tahun mengalami perkembangan yang unik namun daya serap keingintahuan mereka sangat tinggi terhadap media digital, (c) Task Analysis yakni analisis tugas dari pendidik atau analisis pencapain kemampuan pengetahuan orang tua dalam strategi melindungi anak dari bahaya media digital. Usia orang tua rata-rata termasuk dalam generasi X (1965-1980) dan Generasi Y/ milenial (1981-1994) yang belum familiar dengan kecanggihan media digital dan mengalami masa perubahan dari nondigital menuju ahl-hal yang bersifat digital. Oleh karena itu, bagian dari buku ini diperlukan ada gaya pengasuhan anak, keterampilan dalam menghadapi anak generasi alpha dan perlindungan anak di ranah daring, (d) Concept analysis yakni menganalisis konsep yang dituangkan dalam buku ajar, menganalisis tema yang akan memerinci buku ajar digital parenting. Buku ini berangkat dari bahaya kejahatan dunia online pada anak, konsep dari digital parenting, pengasuhan anak pada masa digital, bersahabat dengan media digital dan sinergi dari peran yang dilaksanakan orang tua dan sekolah dalam melindungi anak dari bahaya dunia online, (e) Specifying instructional objectives atau menganalisis konsep tujuan dari buku ajar digital parenting sebagai pengetahuan dan keterampilan orang tua dalam mendidik anak untuk melindungi anaknya dari bahaya media digital.

Langkah yang kedua dari 4 model Thiagrajan adalah perancangan (Design) buku ajar digital parenting. Tahapan ini menghasilkan rancangan buku ajar yang akan dikembangkan dengan memperhatikan kriteria kebutuhan orang tua, pemilihan media dan subjudul dalam buku, pemillihan buku dan desain awal dari produk buku. Rancangan awal dibuat dengan 
memperhatikan hasil analisis dari tahap pendefinisian sehingga kerangka isi yang dibuat dapat sesuai.

Kemudian langkah ketiga dari model Thiagrajan adalah pengembangan (Develop) buku ajar digital parenting. Thiagarajan mengelompokkan tahap pengembangan ini ke dalam dua kegiatan yaitu penilaian dari para pakar dan pengujian pengembangan dari produk buku. Produk yang sudah dibuat dalam tahap desain kemudian dinilai pakar teknologi pembelajaran dan pakar bidang PAUD menggunakan instrumen penilaian yang disesuaikan dengan kebutuhan penelitian. Penilaian expert ini merupakan penilaian dari komponen baik materi, tata bahasa maupun materi isi yang terdapat buku ajar digital parenting. Pakar ahli media dilakukan oleh dosen dari Program Studi PIAUD UIN Sunan Kali jaga Yogyakarta dengan bidang keahlian teknologi pendidikan, media pembelajaran dan bahan ajar. Sedangkan validator ahli materi dilakukan oleh Dr. Diah Andhika Sari, M.Pd. dosen Program Studi PG-PAUD Universitas Muhammadiyah Jakarta dengan bidang keahlian PAUD.

Pada tahap validasi terdapat 10 butir pengamatan yang dinilai pakar yang disesuaikkan pada beberapa aspek pernyataan dengan menggunakan skala penilaian rentang $1-100 \%$. Berdasarkan hasil dari penilaian pakar terhadap buku digital parenting dijadikan pedoman untuk memperbaiki buku tersebut agar lebih dapat dikembangkan kembali. Berdasarkan hasil penilaian validator, maka desain sampul (cover) dalam buku ajar yang dikembangkan sesudah direvisi seperti gambar 2 dan 3.

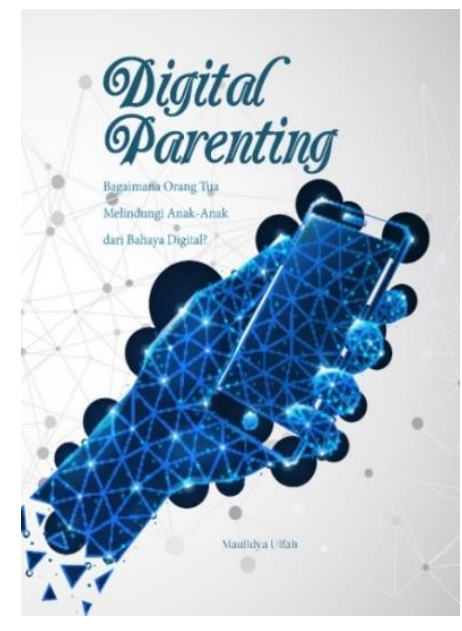

Gambar 2. cover tampak depan

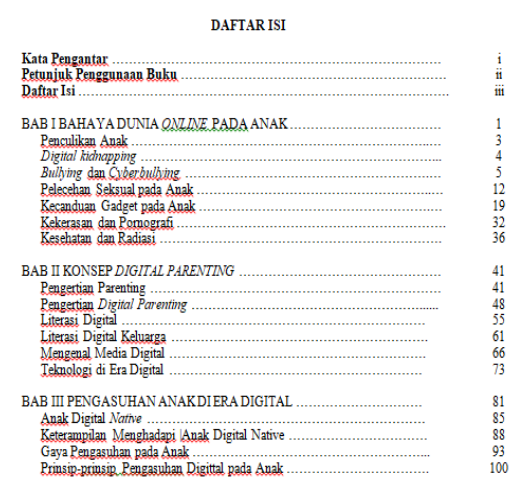

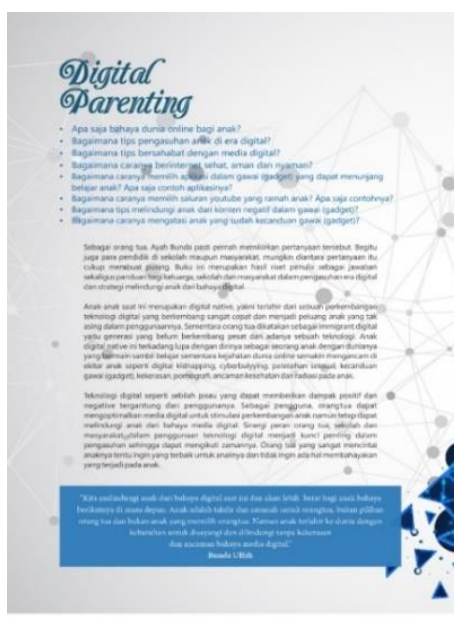

Gambar 3. cover tampak belakang

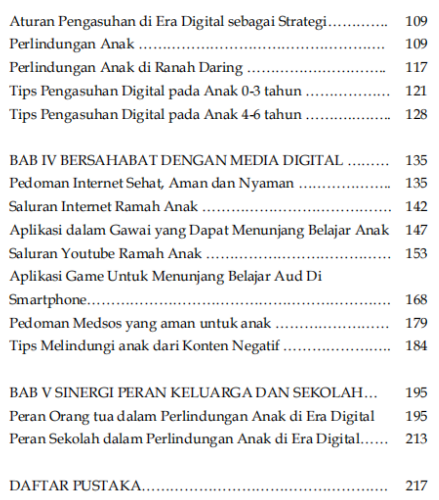

Gambar 4. daftar isi yang sudah direvisi

Hasil penilaian validator pakar ahli media diperoleh nilai rata-rata $85 \%$ sementara dari pakar ahli materi diperoleh nilai-rata-rata yaitu $82 \%$ atau dapat simpulkan sangat valid. Hal ini menjadi temuan bahwa media dan materi yang ada di dalam buku digital parenting sesuai 
dengan konsep pengasuhan anak di era digital. Nilai rata-rata dari setiap indikator buku ajar dapat ditentukan oleh dua orang validator ditampilkan dalam tabel 1.

Tabel 1. Penilaian Validator Pakar Ahli Media terhadap Buku Digital Parenting

\begin{tabular}{clc}
\hline No & \multicolumn{1}{c}{ Butir Penilaian } & $\begin{array}{c}\text { Nilai Rata-rata } \\
(\mathbf{\%})\end{array}$ \\
\hline 1. & Buku ajar memiliki desain sampul (cover) yang menarik dan jelas & 85 \\
2. & Buku ajar memiliki desain isi yang menarik dan jelas & 85 \\
3. & Buku ajar memiliki tata letak (layout) yang menarik dan jelas & 85 \\
4. & Bahasa yang dipakai sesuai KBBI atau PUEBI kaidah bahasa Indonesia & 85 \\
$\mathbf{5 .}$ & Kata yang digunakan dalam buku ajar tidak menimbulkan penafsiran ganda & 90 \\
6. & Tanda baca yang digunakan dalam buku ajar sudah tepat & 90 \\
$\mathbf{7 .}$ & Ukuran huruf (font) yang dipakai dalam buku digital parenting sudah tepat & 85 \\
$\mathbf{8 .}$ & Pemilihan huruf (font) yang dipakai dalam buku digital parenting mudah dibaca & 90 \\
$\mathbf{9 .}$ & Buku ajar memiliki kesesuaian antara gambar dan ilustrasi pada materi & 90 \\
$\mathbf{1 0 .}$ & Buku ajar memiliki kualitas sampul (cover) dan isi yang bagus & 85 \\
\hline & \multicolumn{1}{c}{ Nilai Rata-rata } & $\mathbf{8 5}$ \\
\hline
\end{tabular}

Tabel 2. Penilaian Validator Pakar Materi terhadap Buku Digital Parenting

\begin{tabular}{|c|c|c|}
\hline No & Butir Penilaian & $\begin{array}{c}\text { Nilai Rata-rata } \\
(\%)\end{array}$ \\
\hline 1. & $\begin{array}{l}\text { Buku ajar sudah memuat nilai pendidikan anak usia dini sesuai dengan tujuan } \\
\text { yang ditetapkan }\end{array}$ & 85 \\
\hline 2. & $\begin{array}{l}\text { Buku ajar memuat tema yang komprehensif dan dibutuhkan orang tua maupun } \\
\text { sekolah }\end{array}$ & 85 \\
\hline 3. & $\begin{array}{l}\text { Buku ajar memuat kedalaman materi yang sesuai dengan kemampuan orang tua } \\
\text { maupun sekolah }\end{array}$ & 85 \\
\hline 4. & Buku ajar dilengkapi gambar yang dapat memperjelas materi & 80 \\
\hline 5. & $\begin{array}{l}\text { Kalimat maupun kata yang digunakan dalam buku ajar disajikan secara jelas dan } \\
\text { sistematis }\end{array}$ & 80 \\
\hline 6. & $\begin{array}{l}\text { Buku ajar menggunakan sumber rujukan yang dapat dipertanggungjawabkan } \\
\text { (buku, website dan jurnal) }\end{array}$ & 85 \\
\hline 7. & Buku ajar memiliki penyajian materi yang menarik & 80 \\
\hline 8. & Buku ajar memiliki uraian materi yang jelas dan mudah dipahami & 80 \\
\hline 9. & Buku ajar memuat contoh dan tips yang jelas dengan bahasa yang mudah & 80 \\
\hline 10. & $\begin{array}{l}\text { Buku ajar memiliki muatan konsep yang tekstual dan dikontekstualkan dengan } \\
\text { saat ini }\end{array}$ & 80 \\
\hline
\end{tabular}

Tabel 3. Nilai Rata-rata Penilaian Akhir dari Validator Pakar Ahli

\begin{tabular}{lcc}
\hline \multicolumn{1}{c}{ Indikator } & Nilai Rata-rata & Kategori \\
\hline Kelayakan Media & 85 & Sangat layak/ baik \\
Kelayakan Materi & 82 & Sangat layak/ baik \\
\hline
\end{tabular}

Penilaian buku digital parenting oleh para pakar telah dikategorikan sangat baik atau sangat valid atau sangat layak. Setelah melalui penilaian validasi pakar, peneliti melakukan tahapan sejauh mana keefektifan dan kepraktisan perangkat buku ajar digital parenting saat digunakan orang tua secara langsung dengan uji coba lapangan. Kemudian dilakukan perbaikan-perbaikan dengan masukan dari pengguna.

Sampel orang tua saat uji coba lapangan berjumlah 15 orang di PAUD Aisyiyah Kota Cirebon. Paneliti mendistribusikan buku digital parenting untuk dibaca dan dipelajari bersama kemudian dipraktikkan untuk mendidik anak usia dini. Pada uji coba lapangan ini, peneliti mewancarai dan mengamati respon orang tua dan anak-anak pada saat menerapkan buku ajar digital parenting selama satu bulan. 
Pada saat pertama kali diberikan buku ajar digital parenting, para orang tua antusias dan penasaran. Hal ini terlihat dari sebagian orang tua yang ingin membaca dan menerapkan isi dari buku tersebut dan mulai bertanya tentang media digital parenting. Oleh karena itu, peneliti, teman sejawat dan guru menjelaskan mengenai media tesebut agar para orang tua memahami dan bisa menerapkan buku tersebut. Peneliti dibantu sekolah dalam melakukan uji coba untuk merekam respon orang tua pada saat pemakaian buku ajar digital parenting, Tabel 4 merupakan hasil angket dan pengamatan kepada orang tua.

Tabel 4. Nilai Rata-rata Hasil Penilaian Pengguna

\begin{tabular}{|c|c|c|c|c|c|c|c|c|c|c|}
\hline \multirow[t]{2}{*}{ No } & \multirow{2}{*}{$\begin{array}{c}\text { Nama Orang } \\
\text { Tua }\end{array}$} & \multicolumn{8}{|c|}{ Butir Penilaian } & \multirow[t]{2}{*}{ Jumlah } \\
\hline & & $\mathbf{A}$ & B & $\mathbf{C}$ & D & $\mathbf{E}$ & $\mathbf{F}$ & $\mathbf{G}$ & $\mathbf{H}$ & \\
\hline 1 & NF & 4 & 3 & 3 & 3 & 3 & 3 & 4 & 3 & 26 \\
\hline 2 & UFY & 3 & 4 & 4 & 3 & 4 & 4 & 4 & 4 & 30 \\
\hline 3 & AS & 4 & 4 & 4 & 4 & 4 & 3 & 4 & 4 & 31 \\
\hline 4 & $\mathrm{JZ}$ & 3 & 3 & 3 & 3 & 3 & 3 & 3 & 3 & 24 \\
\hline 5 & ENT & 4 & 3 & 4 & 4 & 4 & 4 & 4 & 4 & 31 \\
\hline 6 & $\mathrm{AM}$ & 3 & 4 & 4 & 4 & 4 & 4 & 4 & 3 & 30 \\
\hline 7 & SYF & 4 & 4 & 4 & 3 & 4 & 4 & 4 & 4 & 31 \\
\hline 8 & UL & 3 & 3 & 3 & 3 & 3 & 3 & 3 & 3 & 24 \\
\hline 9 & YNT & 4 & 4 & 4 & 3 & 4 & 4 & 4 & 4 & 31 \\
\hline 10 & $\mathrm{JG}$ & 4 & 4 & 3 & 4 & 4 & 4 & 4 & 4 & 31 \\
\hline 11 & DS & 4 & 3 & 3 & 3 & 3 & 3 & 4 & 4 & 27 \\
\hline 12 & $\mathrm{KS}$ & 4 & 4 & 3 & 3 & 4 & 4 & 4 & 4 & 30 \\
\hline 13 & MDD & 3 & 3 & 3 & 3 & 4 & 4 & 4 & 4 & 28 \\
\hline 14 & AY & 3 & 3 & 3 & 3 & 3 & 3 & 4 & 4 & 26 \\
\hline \multirow[t]{2}{*}{15} & BDR & 3 & 3 & 3 & 3 & 3 & 3 & 3 & 3 & 24 \\
\hline & & & & & & & . & $\begin{array}{l}\text { ai } \\
\text { lai }\end{array}$ & $\begin{array}{l}\text { Total } \\
\text {-rata } \\
\text {-rata }\end{array}$ & $\begin{array}{c}424 \\
28,267 \\
88.33\end{array}$ \\
\hline
\end{tabular}

Keterangan penilaian pengguna sesudah membaca dan menerapkan buku digital parenting adalah (A) Orang tua mampu memahami isi buku digital parenting, (B) Orang tua mampu mengenal bahaya dari media di era digital, (C) Orang tua mampu memahami pengetahuan tentang pengasuhan di era digital, (D) Orang tua mampu memahami tips menghadapi kejahatan dunia online, (E) Orang tua mampu menerapkan penggunaan media digital untuk melindungi anak, (F) Buku memiliki muatan konsep isi yang lengkap komprehensif, $(\mathrm{G})$ Buku memiliki desain cover dan isi yang menarik dan $\mathrm{H}$ : Buku memiliki jenis huruf, ukuran huruf dan tata letak yang sesuai.

Hasil penilaian orang tua di PAUD Aisyiyah Kota Cirebon (pengguna) terhadap buku digital parenting diperoleh persentase nilai rata-rata $88,3 \%$ dari skor ideal $100 \%$. Saran dari orang tua terhadap buku ini adalah pada tampilan buku, membuat poster tentang penjelasan digital parenting dan bahaya media digital serta masukan kepada sekolah agar menyelenggarakan kegiatan parenting secara terjadwal rutin dengan tema sesuai subjudul dari buku tersebut. Berdasarkan hal tersebut dapat disimpulkan bahwa kepraktisan buku dapat dikatakan tercapai dan layak untuk digunakan.

Tahap terakhir atau keeempat adalah penyebarluasan (disseminate). Tahap penyebarluasan terdiri dari 3 kegiatan yaitu: pengemasan buku digital parenting, difusi dan adopsi. Buku digital parenting yang sudah diimplementasikan kemudian diukur tingkat kepraktisan dan keefektivan dari orang tua dalam menerapkan strategi pengasuhan digital untuk melindungi anak sesuai yang ada di buku. Tahapan ini menjadi kegiatan terakhir dalam penelitian dan pengembangan yaitu melakukan pengemasan (book packaging), difusi dan adopsi. Pengemasan yang dilakukan adalah dengan mencetak buku digital parenting. Buku cetak digital parenting ini memiliki Nomor ISBN 978-623-7610-80-6 dan sudah ada di google play book dengan link: https://s.id/playgooglebukudigitalparenting. Aspek difusi dalam proses 
penyebaran ini adalah buku ini dapat diserap oleh orang tua dan dimanfaatkan oleh satuan PAUD sebagai salah satu pedoman dalam kegiatan kelas-kelas parenting di sekolah.

Hasil penelitian yang dibahas pada artikel ini yaitu dari awal, proses sampai hasil dari pengembangan sebuah buku digital parenting dan kualitas buku dari aspek keefektifan dan kelayakan buku yang telah dikembangkan. Adapun analisis pengembangannya dimulai dari proses pengembangan buku. Menurut Sugiyono bahwa riset dan pengembangan yang dilaksanakan peneliti akan mengeluarkan produk sebuah buku dan mengkaji juga aspek keefektifan buku tersebut. (Sugiyono, 2011) Buku yang dihasilkan dalam R and D ini adalah buku digital parenting menggunakan model pengembangan yaitu $4 \mathrm{D}$ oleh tokoh yang bernama Thiagarajan dengan proses yang dilakukan peneliti adalah 4 tahapan, yakni: penjelasan kebutuhan buku (define), perencanaan produk buku (design), pengembangan buku digital parenting (develop) dan penyebaran buku yang sudah divalidasi (disseminate).(Others et al., 1974) Tahapan ini dimulai dengan melakukan analisis melalui kegiatan observasi dan wawancara terhadap orang tua dan mengamati karakteristik anak-anak untuk dianalisis permasalahan mendasar yang dihadapi dalam proses pengasuhan terhadap anak usia dini.

Buku ajar (Daryanto, 2013)yang dikembangkan ini digunakan untuk orang tua anak usia dini sesuai dengan karakteristik buku dan kebutuhan orang tua serta melalui beberapa proses validasi yaitu ahli materi, ahli media dan pengguna sehingga dihasilkan buku yang valid, praktif dan efektif. Uji kelayakan produk buku dilakukan oleh dua orang pakar bidang teknologi pendidikan dan pakar PAUD sehingga buku yang dirancang dan dikembangkan layak digunakan orang tua anak usia dini. Validasi pakar ahli media ada 10 aspek penilaian dan validasi pakar ahli materi dengan 10 butir penilaian.

Indikator media diperolah dari hasil validitas pakar dengan persentase $85 \%$ atau ratarata sangat layak buku ini bisa diterapkan. Peneliti dapat menganalisis bahwa media tersebut memiliki desain sampul, isi dan layout yang menarik; pemilihan kata yang sesuai dengan PUEBI dalam kaidah Bahasa Indonesia dan tidak memiliki makna ganda dalam kalimat; pemilihan jenis huruf, ukuran huruf dan tanda baca yang tepat. Sedangkan indikator materi dari validatas pakar memperoleh nilai persentase $82 \%$ atau dikatakan sangat valid untuk dapat diterapkan untuk orang tua. Peneliti dapat menganalisis bahwa media tersebut memenuhi butir pengamatan diantaranya subjudul yang komprehensif, kedalaman materi yang sesuai dengan kebutuhan orang tua, kalimat yang jelas dan sistematis, sumber pustaka yang valid dan bisa dipertanggungjawabkan, materi yang menarik, jelas dan mudah dipahami yang dilengkapi dengan contoh dan tips pengasuhan anak di era digital.

Sesudah validasi pakar dengan hasil yang "sangat baik" kemudian dilakukan ujicoba produk penggunaan buku digital parenting dengan melibatkan 15 orang tua sebagai uji coba. Peneliti dapat menganalisis sesudah melakukan wawancara dan pengamatan pada orang tua selama sebulan dengan penilaian dari orang tua PAUD Aisyiyah Kota Cirebon yakni sangat baik dengan persentase $88,3 \%$ atau dikatakan sangat baik. Berdasarkan nilai tersebut, maka peneliti dapat menyimpulkan bahwa buku tersebut dapat dimanfaatkan oleh orang tua sebagai strategi perlindungan anak, orang tua terlihat antusias dan tertarik untuk membaca buku tersebut untuk menambah pengetahuan tentang pengasuhan anak di era digital.

Analisis pembahasan yang kedua adalah kualitas buku ajar. Fleming and Leview mengemukakan bahwa produk pembelajaran yang berkualitas terdiri dari 5 hal pokok, yaitu penjabaran materi yang di dalam jelas dilengkapi dengan petunjuk yang memudahkan pembaca, tampilan media harus disesuaikan dengan tema, materi isi sesuai dan tidak berlebihan, kebenaran dari materi tersebut dapat dipertanggungjawabkan, tampilan media sesuai dengan aturan baku. (Nesbit \& Leacock, 2007) Hal ini dianalogikan seperti buku yang membantu orang tua dalam mengingat pengamalan, memaparkan secara jelas isi kandungan buku, mengubah kesalahpahaman yang ada dalam diri orang tua, membuka mindset yang baru dengan wawasan kekinian dan dapat memberikan manfaat dalam setiap kalimat maupun kata yang dapat menjadi dasar penentuan proses maupun dasar dari sebuah hasil penilaian.(Oladumiyte, 2014) 
Buku digital parenting berisikan halaman sampul (cover), kata pengantar, daftar isi, dan bagian isi yaitu: (1) Sub bab isi tentang ancaman media digital pada anak yang terdiri dari bahaya dunia online yang mengancam anak-anak, diantaranya adalah penculikan anak, digital kidnapping, bullying dan cyberbullying, pelecehan seksual pada anak, kecanduan gadget, bahaya kekerasan dan pornografi pada anak serta bahaya kesehatan pada anak dan radiasi dari gawai (gadget). Buku ini sebagai salah satu strategi untuk melindungi anak dari dampak negatif media digital yaitu digital kidnapping, cyberbulllying, child grooming, kecanduan gawai, pornografi, bahaya kesehatan dan radiasi. Martin Davies, seorang profesor di Universitas East Anglia Inggris, menjelaskan bahwa parenting merupakan pendidikan sejak lahir pada anak sampai anak dewasa dengan kriteria yang ditentukan tidak sekedar pertumbuhan fisik namun dewasa baik mental maupun psikologis. Parenting merupakan komunikasi dan interaksi antara orang tua dengan anak-anak yang mencakup kegiatan memberikan perlindungan (protecting), memberikan petunjuk (guiding), memberikan nutrisi makanan (nourishing), saat tumbuh kembang anak-anak (Yani et al., 2017). Perlindungan menjadi bagian dari pengasuhan dengan memenuhi hak anak, tumbuh kembang, melindungi dari kekerasan dan diskriminasi, ancaman yang dapat membahayakan anak (Ulfah, 2019)(Risma et al., 2019). Kesesuaian isi buku ini menjadi penting untuk dibahas karena yang bertanggung jawab dalam melindungi anak adalah pemerintah, Negara, keluarga, masyarakat termsuk didalamnya lembaga pendidikan. (Kuswanti et al., 2017).

Bagian selanjutnya dari buku ini adalah sub bab isi tentang konsep digital parenting yang terdiri dari pengertian parenting, pengertian digital parenting, literasi digital, literasi digital keluarga, mengenal media digital dan teknologi di era digital. Sub bab isi tentang pengasuhan anak di era digital terdiri dari sub tema anak digital native, keterampilan menghadapi anak digital native, gaya pengasuhan pada anak, prinsip-prinsip pengasuhan digital pada anak, aturan pengasuhan di era digital sebagai strategi perlindungan anak, perlindungan anak di ranah daring, tips pengasuhan digital pada anak usia 0-3 tahun dan 4-6 tahun (Nurwita, 2019). Pengasuhan yang baik adalah mereka yang siap untuk mengasuh anak untuk generasi berikutnya dengan memberi rasa aman dasar menjelajahi dunia mereka (Hughes \& Baylin, 2012). Dalam hal ini termasuk di dalamnya melindungi anak dari pengaruh negatif lingkungan sekitar. Pengetahuan pengasuhan ini sangat dibutuhkan orang tua karen budaya di sekitar anak dapat mengubah perilakunya menjadi negatif, dan pondasi agama diperlukan dalam mendidik anak karena orang tua akan dimintai pertanggungjawaban (Beshir \& Ekram, 2014).

Sub bab isi tentang bersahabat dengan media digital yang terdiri dari pedoman internet sehat, aman dan nyaman (website, playstore, youtube), saluran internet ramah anak, aplikasi yang dapat menunjang belajar anak, saluran youtube ramah anak, aplikasi dalam game untuk menunjang belajar anak usia dini di smartphone, pedoman media sosial yang aman untuk anak (facebook, instagram), tips melindungi anak dari konten negatif (playstore, youtube, facebook, instagram). Orang tua yang dapat bersahabat dengan anak dalam merespon cepatnya arus perkembangan dunia digital (Purnama, Syukriyah, et al., 2021), juga dapat membangun pola komunikasi dengan anak untuk membangun keterikatan yang dapat mempengaruhi perkembangan anak (Siegel, 2014). Orang tua dapat belajar bersahabat dengan media digital dan berkomunikasi dengan anak untuk melindungi mereka dari dampak negatif media digital.

Sub bab isi tentang peran keluarga dan sekolah dalam melindungi anak di era digital memiliki sub bab kerja sama dari sinergi yang dilakukan orang tua dan sekolah dalam melakukan strategi perlindungan pada anak terhadap tantangan bahaya dunia online. Sinergi peran orang tua dan sekolah ini mengacu pada Peraturan yang dikeluarkan oleh Presiden Nomor 60 pada tahun 2013 dalam menerapkan PAUD berbasis pendekatan HI atau holistik integratif(Peraturan Presiden Nomor 60 Tahun 2013 Tentang Pengembangan Anak Usia Dini Yang Holistik Integratif, n.d.) dengan melayani stimulasi layanan pendidikan anak, kesehatan dan gizi seimbang, perawatan pada anak, pengasuhan yang diterapkan, strategi perlindungan 
anak dan kesejahteraan (Peraturan Presiden Nomor 60 Tahun 2013 Tentang Pengembangan Anak Usia Dini Yang Holistik Integratif, n.d.). Keberhasilan dalam mewujudkan PAUD HI ini didukung oleh partisipasi orang tua dalam mengikuti kegiatan di sekolah (Ulfah, 2019). Salah satu dukungan tersebut adalah program parenting sebagai wadah komunikasi antara orang tua dengan sekolah agar memberikan pendidikan dan pengasuhan terbaik untuk anakanaknya (Ulfah et al., 2018). Program parenting juga dibutuhkan untuk mempersiapkan generasi emas pada tahun 2045 yang memiliki karakter pengembangan moral berbasiskan norma Islam dalam rangka mewujudkan generasi masa depan yang sholikh sholikhah (Yani et al., 2017).

Karakter yang diharapkan sesuai dengan fitrah yang ada (Purnama et al., 2020) dan yang dijelaskan Thomas Lickona bahwa secara etimologis karakter seseorang itu adalah " $a$ reliable inner disposition to respon situation in a morally good way," yakni berpedoman pada serangkaian perilaku seseorang (behavior), sikap yang dimiliki (attitudes), tingkat pengetahuannya (cognitives) dan motivasi (motivations) dan keterampilan (Marzuki, n.d.). Subsub bab di atas menjadikan buku ajar digital parenting memiliki keunggulan penyajian yang lengkap tentang pengasuhan di era digital dengan materi dimulai dari bahaya media digital atau kejahatan yang dapat terjadi dari dunia online. Buku ini juga mengajak kepada orang tua dalam pengasuhan digital, pemanfaatan media digital secaran aman, sehat dan menyenangkan untuk stimulasi perkembangan anak.

Buku ajar digital parenting pada anak usia dini harus diterapkan orang tua dengan cara bermain sambil belajar bukan sekedar pemberian nasehat saja. Orang tua harus mampu memberikan contoh kepada anak dalam pemanfaatan media digital. Oleh karena itu, penelitian ini menjadi bagian dari sebuah proses untuk mengembangkan buku ajar ataupun modul untuk orang tua dan guru dalam menambah wawasan ilmu parenting agar lebih baik lagi dalam melindungi dan menstimulasi tumbuh kembang anak.

\section{SIMPULAN}

Penelitian ini menghasilkan buku digital parenting yang komprehensif sebagai sebuah strategi untuk melindungi anak dari dampak negatif penggunaan media digital. Hal ini mengacu pada teori Diana Baumrind bahwa parental control dibutuhkan, yaitu orang tua dapat mengontrol, membimbing dan mendampingi anak dalam melaksanakan tugas perkembangan. Buku ini dapat menjawab kecemasan orang tua menghadapi tantangan kejahatan dunia online akibat negatif dari kemajuan teknologi yang dapat mengganggu tumbuh kembang anak. Riset pengembangan buku menunjukkan hasil sangat layak berdasarkan penilaian pakar PAUD dan ujicoba pada orang tua. Buku ini dapat dimanfaatkan untuk orang tua maupun sekolah guna melindungi anak-anak.

\section{UCAPAN TERIMA KASIH}

Ucapan terima kasih kami sampaikan kepada Rektor dan Ketua LP2M Institut Agama Islam Negeri (IAIN) Syekh Nurjati Cirebon yang telah mendanai riset ini melalui DIPA IAIN Tahun 2019. Tidak lupa pula kepada Pakar Ahli Validator Buku, Lembaga PAUD di Cirebon dan rekan mahasiswa yang menjadi relawan pengumpul data, semoga menjadi amal sholeh yang dinilai Allah SWT. Reviewer dan Editor Jurnal Obsesi: Jurnal Pendidikan Anak Usia Dini, atas masukan yang diberikan sehingga artikel ini dapat dipublikasikan.

\section{DAFTAR PUSTAKA}

Adelman, A. J., \& Adelman, A. J. (2018). Parenting in the digital age. Psychoanalytic Reflections on Parenting Teens and Young Adults, October, 7-37. https://doi.org/10.4324/9781351262767-2

Agung, A. P. D., Sepud, I. M., \& Dewi, A. A. S. L. (2020). Sanksi Pidana terhadap Pelaku Penculikan Anak. Jurnal Preferensi Hukum, 1(2), 195-195. https://doi.org/10.22225/jph.1.2.2388.195$\underline{195}$ 
Alia, T., \& Irwansyah, I. (2018). Pendampingan Orang Tua pada Anak Usia Dini dalam Penggunaan Teknologi Digital [Parent Mentoring of Young Children in the Use of Digital Technology]. Polyglot: Jurnal Ilmiah, 14(1), 78. https:// doi.org/10.19166/pji.v14i1.639

Barbour, I. G. (2002). Juru Bicara Tuhan Antara Sains dan Agama. Mizan.

Basiang, M. (2016). The Contemporary Law Dictionary. Gramedia Pustaka Utama.

Baumrind, D. (1966). Effects of Authoritative Parental Control on Child Behavior. Child Development, 37(4), 907. https://doi.org/10.2307/1126611

Beshir, M. R., \& Ekram. (2014). Parenting Skill: Based on The Qur'an and Sunnah. Amana Publications.

Bronfenbrenner, U. (1994). Ecological Models of Human Development. In In International Encyclopedia of Education (Vol. 3, Issue 2). Elsevier.

Daryanto. (2013). Menyusun Modul (Bahan Ajar untuk Persiapan guru dalam Mengajar. Gava Media.

Donnyanggoro, K. Y., Gogor Bangsa, P., \& Malkisedek, M. H. (2018). Perancangan Iklan Layanan Masyarakat Dampak Negatif Penggunaan Gadget Secara Berlebihan terhadap Tubuh. Jurnal DKV Adiwarna, 1(12), 1-9.

Fatonah, R., Setiawan, A., \& Andrisman, T. (2019). Analisis Perlindungan Hukum terhadap Anak Korban Penculikan oleh Tenaga Pendidik di Lampung Selatan. Jurnal Poenale, 7(3).

Hamzah, N. H., Khomaeny, E. F. F., \& Ulfa, M. (2021). Tontonan anak di Televisi: Paradoks dan Kontestasi Nilai Tontonan Anak di Media Televisi Nasional. Jurnal Obsesi : Jurnal Pendidikan Anak Usia Dini, 5(2), 1883-1893. https://doi.org/10.31004/obsesi.v5i2.713

Hayati, F., \& Mamat, N. (2014). Pengasuhan dan Peran Orang Tua (Parenting) serta Pengaruhnya terhadap Perkembangan Sosial Emosional Anak di PAUD Banda Aceh, Indonesia. Jurnal Buah Hati, 1(2), 30. https:/ / doi.org/10.46244/BUAHHATI.V1I2.523

Hughes, D. A., \& Baylin, J. (2012). Brain-Based Parenting The Neuriscience of Caregiving for Healthy Attachment. Norton Professional Book.

Kuswanti, E. P., Yuliantina, I., Nurfadillah, Handayani, I., \& Susilowat, T. (2017). Layanan Perlindungan dan Kesejahteraan. Direktorat Pendidikan Anak Usia Dini dan Pendidikan Masyarakat.

Maisari, S., \& Purnama, S. (2019). Peran Digital Parenting Terhadap Perkembangan Berpikir Logis Anak Usia 5-6 Tahun Di Ra Bunayya Giwangan. Awlady: Jurnal Pendidikan Anak. https://doi.org/10.24235/awlady.v5i1.4012

Manik, N. L. A., \& Widhiyaastuti, I. G. A. A. D. (2019). Penanganan Korban TIndak Pidana Penculikan terhadap Anak di Wilayah Polda Bali. Kertha Wicara: Journal Ilmu Hukum, 8(12), 1-15.

Mansur. (2009). Pendidikan Anak Usia Dini dalam Islam. Pustaka Pelajar.

Marzuki. (n.d.). Prinsip Dasar Pendidikan Karakter Perspektif Islam.

Maulidya Ulfah, Ery Khaeriyah, N. B. S. (2018). Implementasi Program Parenting dalam Menanamkan Nilai Moral Anak Unisa Dini. Indonesian Journal of Islamic Early Childhood Education, 3(2).

Nesbit, J. C., \& Leacock, T. L. (2007). A Framework for Evaluating the Quality of Multimedia Learning Resources. Journal of Educational Technology \& Society, 10(2), 44-59.

Nurwita, S. (2019). Analisis Nilai-Nilai Agama dan Moral Anak Usia Dini dalam Tayangan Film Kartun Upin dan Ipin. Jurnal Obsesi : Jurnal Pendidikan Anak Usia Dini, 3(2), 506. https://doi.org/10.31004/obsesi.v3i2.252

Oladumiyte, E. B. (2014). Graphics Communication an Appraisal of an Art of Learning in Contemporary Nigerian Education. Art and Design Review, 02(03), 29-39. https://doi.org/10.4236/adr.2014.23005

Others, A., Thiagarajan, \& Sivasailam. (1974). Instructional Development for Training Teachers of Exceptional Children: A Sourcebook. Indiana Univ., Bloomington. Center for Innovation in Teaching the Handicapped. National Center for Improvement of Educational Systems (DHEW/OE). National Center for Improvment of Educational System (DHEW/OE).

Peraturan Menteri Negara Pemberdayaan Perempuan dan Perlindungan Anak Nomor 2 tahun 2011 tentang Pedoman Penanganan Anak Korban Kekerasan. (n.d.). 
Peraturan Presiden Nomor 60 tahun 2013 tentang Pengembangan Anak Usia Dini yang Holistik Integratif. (n.d.).

Pertiwi, M. S., Sanubari, T. P. E., \& Putra, K. P. (2018). Gambaran Perilaku Penggunaan Gawai dan Kesehatan Mata Pada Anak Usia 10-12 Tahun. Jurnal Keperawatan Muhammadiyah, 3(1), 28-34. https://doi.org/10.30651/jkm.v3i1.1451

Purnama, S. (2018). Pengasuhan Digital untuk Anak Generasi Alpha AH-PIECE. Al Hikmah Proceedings an Islamic Early Childhood Education.

Purnama, S., 'Aziz, H., Nurhusna, L., \& Ulfah, M. (2020). The Concept of Fitrah for Children in Ibn Katsir's Qur'an Exegesis: A Pedagogical Implication in Early Childhood Islamic Education. Jurnal Pendidikan Islam, 9(1). https://doi.org/10.14421/jpi.2020.91.79-104

Purnama, S., Syukriyah, N., Ulfah, M., Arifuddin, A., \& Aziz, H. (2021). Augmented Reality in Education in Era 4.0. https:// doi.org/10.4108/eai.4-11-2020.2304649

Purnama, S., Ulfah, M., Machali, I., Wibowo, A., \& Narmaditya, B. S. (2021). Does digital literacy influence students' online risk? Evidence from Covid-19. Heliyon, 7(6). https://doi.org/10.1016/j.heliyon.2021.e07406

Rahmat, S. T. (2018). Pola Asuh yang Efektif untuk Mendidik Anak di Era Digital. Jurnal Pendidikan Dan Kebudayaan Missio, 10(2), 143-161.

Ratulia, M. (2015). Digital Parenthink Tips Mengasuh Kids Zaman Now. Noura Book.

Riset Kominfo dan UNICEF Mengenai Perilaku Anak dan Remaja dalam Menggunakan Internet. (2014). In Kementerian Komunikasi dan Informatika Republik Indonesia.

Risma, D., Solfiah, Y., \& Satria, D. (2019). Pengembangan Media Edukasi Perlindungan Anak untuk Mengurangi Kekerasan pada Anak. Jurnal Obsesi : Jurnal Pendidikan Anak Usia Dini, 4(1), 448-462. https://doi.org/10.31004/obsesi.v4i1.322

Rochmawati, N. I., \& Susilo, A. B. (2019). Pencegahan Kekerasan Terhadap Anak Usia Dini di TK IT Bintang Kecil Kota Semarang. PERNIK: Jurnal Pendidikan Anak Usia Dini, 1(01), 111. https://doi.org/10.31851/pernik.v1i01.2679

Setiani, R. E. (2016). Pendidikan Anti Kekerasan untuk Anak Usia Dini: Konsepsi dan Implementasinya. Golden Age: Jurnal Ilmiah Tumbuh Kembang Anak Usia Dini, 1(2), 3956. https://doi.org/10.14421/iga.2016.12-04

Setyawan, D. (2019). KPAI Sebut Pelanggaran Hak Anak Terus Meningkat. Komisi Perlindungan Anak Indonesia (KPAI).

Siegel, D. J. (2014). Parenting from the Inside Out. The Penguin Group.

Sugiyono. (2011). Metode Penelitian Kuantitatif, Kualitatif dan R\&D. Alfabeta.

Sugiyono. (2012). Metode Penelitian Pendidikan. Alfabeta.

Ulfa Maulidya, S. (2017). Konsep Dasar PAUD. PT Remaja Rosdakarya.

Ulfah, M. (2019). Pendekatan Holistik Integratif Berbasis Penguatan Keluarga pada Pendidikan Anak Usia Dini Full Day. Jurnal Obsesi : Jurnal Pendidikan Anak Usia Dini, 4(1). https://doi.org/10.31004/obsesi.v4i1.255

Ulfah, M. (2020). Digital Parenting: Bagaimana Orang Tua Melindungi Anak dari Bahaya Digital? (N. Hamzah (Ed.)). Edu Publisher.

Ulfah, M., Khaeryah, E., \& Sakinah, N. B. (2018). Implementasi Program Parenting dalam Menanamkan Nilai Moral Anak Usia Dini. Indonesian Journal of Islamic Early Childhood Education (IJIECE), 3(2), 173-182. https://doi.org/10.24252/nananeke.v3i2.17469

Undang-Undang RI No. 35 tahun 2014. (2014). Perubahan atas Undang-Undang Nomor 23 Tahun 2002 Tentang Perlindungan Anak.

Wahyuni, V., \& Pransiska, R. (2019). Perilaku Bullying pada Anak Usia 5-6 Tahun Studi Kasus di Taman Kanak-Kanak. JFACE: Journal of Family, Adult, and Early Childhood Education, 1(2), 160-166. https://doi.org/10.5281/zenodo.2650150

Yani, A., Khaeriyah, E., \& Ulfah, M. (2017). Implementasi Islamic Parenting dalam Membentuk Karakter Anak Usia Dini di RA At-Taqwa Kota Cirebon. AWLADY : Jurnal Pendidikan Anak, 3(1), 153-174. https://doi.org/10.24235/awlady.v3i1.1464 